\title{
A Biocompatible Nanocomposite for Glucose Sensing
}

\author{
Parvaneh Rahimi, ${ }^{1,2}$ Hedayatollah Ghourchian, ${ }^{1}$ Hossain-Ali Rafiee-Pour, ${ }^{1}$ \\ Parviz Norouzi, ${ }^{2}$ and Mohammad Reza Ganjali ${ }^{2}$
}

\author{
${ }^{1}$ Laboratory of Microanalysis, Institute of Biochemistry and Biophysics, University of Tehran, \\ Tehran 1417614411, Iran \\ ${ }^{2}$ Center of Excellence in Electrochemistry, Faculty of Chemistry, University of Tehran, \\ Tehran 1417614411, Iran
}

Correspondence should be addressed to Hedayatollah Ghourchian, hadi@ibb.ut.ac.ir

Received 7 February 2011; Accepted 28 February 2011

Academic Editor: Sibel A. Ozkan

Copyright (๑) 2011 Parvaneh Rahimi et al. This is an open access article distributed under the Creative Commons Attribution License, which permits unrestricted use, distribution, and reproduction in any medium, provided the original work is properly cited.

\begin{abstract}
A nanocomposite containing amine functionalized multiwalled carbon nanotubes and a room temperature ionic liquid (1-butyl3-methylimidazolium tetrafluoroborate) was prepared and applied for glucose oxidase (GOx) immobilization on glassy carbon electrode. The proposed nanocomposite provided a favorable microenvironment to preserve the bioactivity of GOx. It could also effectively facilitate the enzyme direct electron transfer to the electrode. This brought about a remarkable improvement in the sensitivity of the glucose biosensor. Under the optimum experimental conditions, the formal potential of GOx was about $-467.5 \mathrm{mV}$. Moreover, the sensitivity and response time of the biosensor toward glucose were $1277 \mu \mathrm{AmM} \mathrm{m}^{-1} \mathrm{~cm}^{-2}$ and $6 \mathrm{~s}$, respectively. The biosensor provided a linear dynamic response between 0.1 and $43 \mu \mathrm{M}$ with a very low detection limit of $63 \mathrm{nM}$. Also, the values for apparent Michaelis-Menten constant and maximum current were obtained as $18 \mu \mathrm{M}$ and $2.7 \mu \mathrm{A}$, respectively.
\end{abstract}

\section{Introduction}

Nanoscale materials have been considerably contributing to biosensor design in recent years. Carbon nanotubes (CNTs) as an example of nanoscale material are broadly used for the fabrication of electrochemical biosensor owing to their outstanding properties [1]. Wang and Musameh [2] reported the first CNTs/enzyme electrodes for glucose and ethanol by incorporating glucose oxidase (GOx) and alcohol dehydrogenase within a three-dimensional CNTs/Teflon matrix. The electrocatalytic properties of CNTs and their ability to promote direct electron transfer between redox proteins and electrode surface were explained by Compton's group [3].

Room temperature ionic liquids (RTILs) are a new class of nonaqueous solvent that consist of an organic cation and either an organic or an inorganic anion. They have unique characteristics such as high conductivity, nonvolatile nature, low toxicity, large electrochemical window, strong electrostatic field, and good electrochemical stability [4]. Because of special properties of RTILs, their applications are increasing in different fields [5] especially for improvement in enzyme electron transfer rate and stability $[4,6,7]$.

By combination of CNTs and RTILs, attractive nanocomposites could be obtained which are useful for the study of protein direct electrochemistry [8-10]. These nanocomposites show high sensitivity and good biocompatibility. Different methods have been developed for fabricating CNTs/ RTILs nanocomposite-based biosensors including electrode modification by RTIL/CNTs/polymer, layer-by-layer selfassembly, CNTs/RTIL pastes, or dispersion of RTIL/CNTs [8].

So far, different types of CNTs/RTIL/GOx nanocomposites have been used for the development of glucose biosensors [11-13]; nevertheless, in the present study we designed a new nanocomposite based on the amine functionalized MWCNTs $\left(\mathrm{NH}_{2}\right.$-MWCNTs). This nanocomposite consists of a typical RTIL, $\mathrm{NH}_{2}$-MWCNTs, and GOx. The proposed nanocomposite not only provided a favorable microenvironment to preserve the bioactivity of GOx but also could effectively facilitate the enzyme direct electron transfer to the 


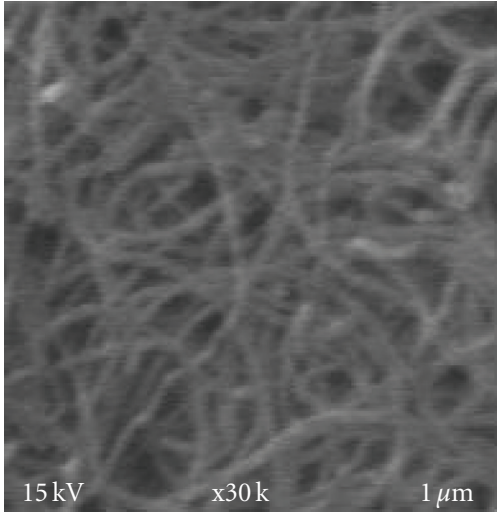

(a)

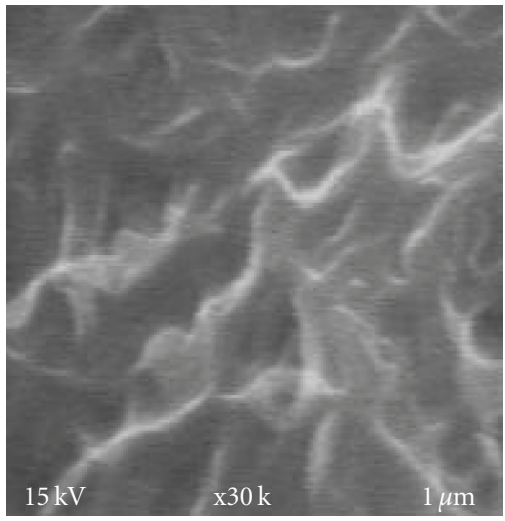

(b)

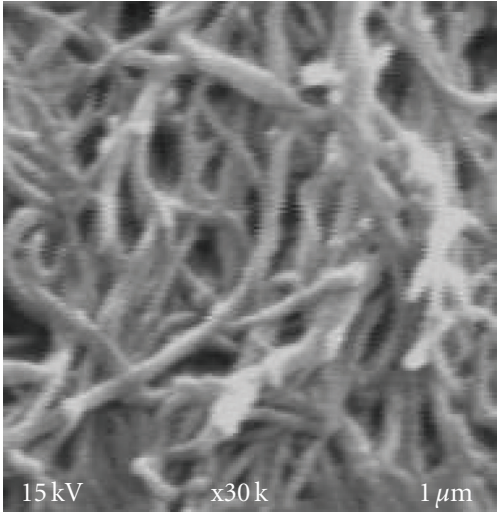

(c)

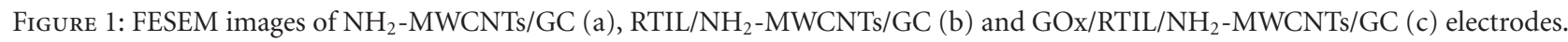

electrode. The fast and easy electron transfer brought about a remarkable improvement in sensitivity of the biosensor toward glucose.

\section{Experimental}

2.1. Materials and Methods. GOx type X-S from Aspergillus niger (EC 1.1.3.4,), $\beta$-D(+)glucose, and 1-butyl-3-methylimidazolium tetrafluoroborate $\left([\mathrm{BMIM}] \mathrm{BF}_{4}\right)$ as a typical RTIL were purchased from Sigma (U.S.A) and used without further purification. Multiwall carbon nanotubes (MWCNTs), prepared by chemical vapor deposition, were supplied by Timesnano. Co. (China). $\mathrm{K}_{4}\left[\mathrm{Fe}(\mathrm{CN})_{6}\right], \mathrm{K}_{3}\left[\mathrm{Fe}(\mathrm{CN})_{6}\right]$, $\mathrm{KCl}, \mathrm{KH}_{2} \mathrm{PO}_{4}, \mathrm{~K}_{2} \mathrm{HPO}_{4}$, and $\mathrm{C}_{2} \mathrm{H}_{4}\left[\mathrm{NH}_{2}\right]_{2}$ were purchased from Merck. Thionyl chloride $\left(\mathrm{SOCl}_{2}\right)$ was supplied by Acros Organics (Belgium). $\beta$-D-glucose solutions were stand overnight to allow equilibration of the monomers. All solutions were prepared in double-distilled deionized water.

Electrochemical studies were carried out using an electrochemical system (EG\&G model 263A potentiostat/galvanostat) controlled by a PowerSuite software package and a GPIB interface. All electrochemical studies were carried out using a conventional three-electrode cell. It was equipped with a modified glassy carbon (GC) electrode (bare or modified with nanocomposites film, from Azar Electrode, Uromia, Iran), a saturated $\mathrm{Ag} / \mathrm{AgCl}$ (3 $\mathrm{M} \mathrm{KCl}$ solution) reference electrode (from Metrohm), and a platinum wire counter electrode. Field emission scanning electron microscopic (FESEM) images were obtained using an FESEM model S4160, Hitachi, Japan. Electrochemical impedance measurements were carried out on a PGSTAT30/FRA2 system (Autolab, Netherlands) in $2 \mathrm{mM} \mathrm{K}_{3}\left[\mathrm{Fe}(\mathrm{CN})_{6}\right] / \mathrm{K}_{4}\left[\mathrm{Fe}(\mathrm{CN})_{6}\right]$ and the frequency range from $10^{-2}$ to $10^{5} \mathrm{~Hz}$.

2.2. Immobilization of Enzyme. The GC electrode $(2 \mathrm{~mm}$ in diameter) was first polished mechanically with 0.3 and $0.05 \mu$ alumina slurry, respectively, and sonicated in water and ethanol, successively.

MWCNTs were amine functionalized based on the method described in our previous work [14]. For GOx immobilization, first $1 \mathrm{mg}$ of $\mathrm{NH}_{2}$-MWCNTs was dispersed in $1 \mathrm{~mL}$ of dimethylformamide using an ultrasonic bath to give a black suspension. Then, $2.5 \mu \mathrm{L}$ of the suspension was transferred onto the cleaned GC electrode and dried in air. The $\mathrm{NH}_{2}-\mathrm{MWCNT} / \mathrm{GC}$ electrode was immersed in pure [BMIM] $\mathrm{BF}_{4}$ solution for $10 \mathrm{hrs}$ at $4^{\circ} \mathrm{C}$ to adsorb a layer of RTIL. At this time, a $6 \mathrm{mg} / \mathrm{mL}$ solution of GOx was prepared in phosphate buffer solution (PBS), $0.1 \mathrm{M}, \mathrm{pH}$ 7.0. Finally, the modified electrode was immersed in GOx solution for $10 \mathrm{hrs}$ at $4^{\circ} \mathrm{C}$. Thereafter, the modified electrode (denoted as GOx/RTIL/NH $\mathrm{NH}_{2}-\mathrm{MWCNT/GC)}$ was rinsed with PBS and stored at $4^{\circ} \mathrm{C}$ when not in use.

\section{Results and Discussion}

3.1. Characterization of Immobilized Enzyme on Modified Electrode. Figure 1 shows the FESEM images of (a) $\mathrm{NH}_{2}$ MWCNTs/GC, (b) RTIL/NH $\mathrm{N}_{2}$-MWCNTs/GC, and (c) GOx/ RTIL/ $\mathrm{NH}_{2}-\mathrm{MWCNTs} / \mathrm{GC}$ modified electrodes. Figure 1(a) represents the image of $\mathrm{NH}_{2}$-MWCNTs as bundles, which are entangled with one another. A mass of RTIL are embedded into the gaps of the formed $\mathrm{NH}_{2}$-MWCNTs network structure (Figure 1(b)). These FESEM images are similar to those obtained by previous workers for MWCNTs/GC and RTIL/MWCNTs/GC electrodes [9]. Figure 1(c) shows the image of the RTIL/ $\mathrm{NH}_{2}-\mathrm{MWCNT} / \mathrm{GC}$ electrode after addition of GOx solution and rinsing the uninteracted materials. Therefore, as shown, the bundles were untangled and uniformly covered the surface of GC electrode. This could be an evidence for successful enzyme immobilization.

The electrochemical impedance spectroscopy can provide useful information on the interfacial changes at the electrode surfaces during the fabrication process. In order to illustrate the role of RTIL/ $\mathrm{NH}_{2}-\mathrm{MWCNTs}$ nanocomposite in electron transferring of GOx, the Nyquist plots for different modified electrodes were recorded (Figure 2). Before GOx immobilization, the bare GC (curve a), $\mathrm{NH}_{2}$-MWCNTs/GC (curve b), and RTIL/ $\mathrm{NH}_{2}$-MWCNTs/GC (curve c) electrodes showed no resistance. But, in the presence of GOx, due to hindered pathway of electron transfer, the 


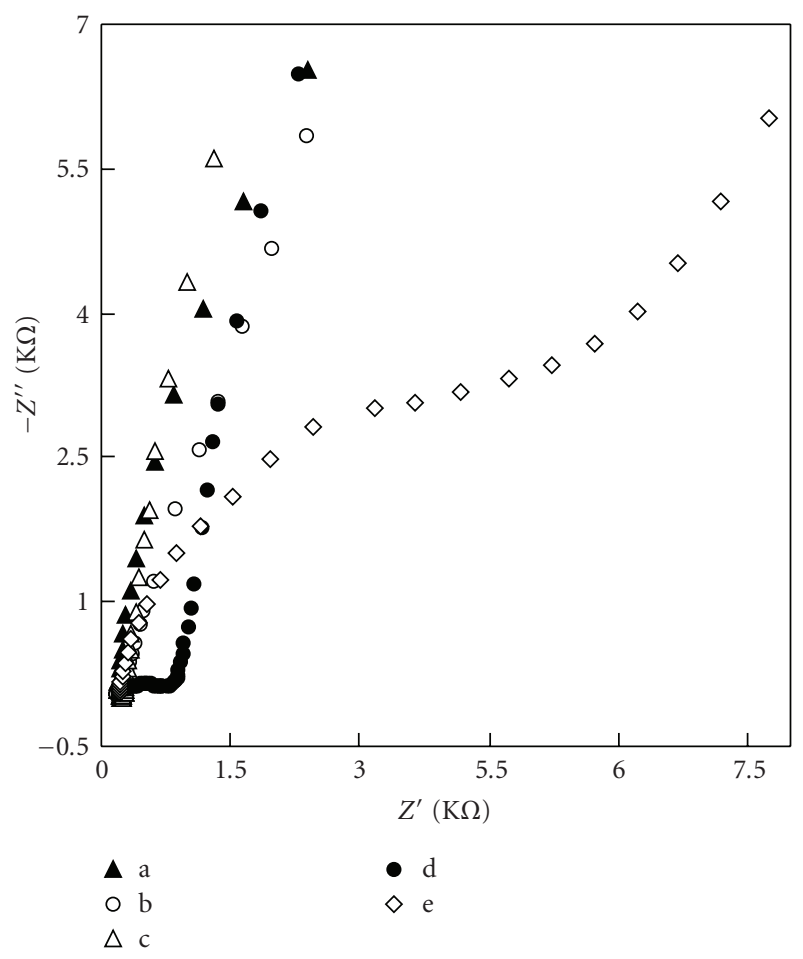

FIgURE 2: Electrochemical impedance spectra of (a) bare GC, (b) $\mathrm{NH}_{2}-\mathrm{MWCNTs} / \mathrm{GC}$, (c) RTIL/NH $\mathrm{N}_{2}-\mathrm{MWCNTs} / \mathrm{GC}$, (d) $\mathrm{GOx} / \mathrm{RTIL} / \mathrm{NH}_{2}-\mathrm{MWCNTs} / \mathrm{GC}$, and (e) GOx/GC electrodes in $0.1 \mathrm{M} \mathrm{KCl}$ solution containing $2 \mathrm{mM} \mathrm{K}_{3}\left[\mathrm{Fe}(\mathrm{CN})_{6}\right] / \mathrm{K}_{4}\left[\mathrm{Fe}(\mathrm{CN})_{6}\right]$.

resistance increased as expected for protein immobilized layer. As shown in Figure 2, the interfacial resistance of the GOx/RTIL/ $\mathrm{NH}_{2}$-MWCNTs/GC electrode was $\sim 1000 \Omega$ (curve $\mathrm{d}$ ), while the resistance value of GOx/GC electrode increased to $\sim 5000 \Omega$ (curve e). This result indicates that the RTIL/ $\mathrm{NH}_{2}-\mathrm{MWCNTs}$ nanocomposite accelerates the electron transfer between GOx active site and the GC electrode surface.

3.2. Electrochemical Behavior of GOx on $\mathrm{RTIL} / \mathrm{NH}_{2}-$ $M W C N T / G C$. To consider the electrochemical behavior of GOx immobilized on RTIL/ $\mathrm{NH}_{2}$-MWCNTs nanocomposite, cyclic voltammetry was used. Figure 3 shows the cyclic voltammograms (CVs) of different electrodes in $0.1 \mathrm{M}$ $\mathrm{N}_{2}$-saturated PBS, $\mathrm{pH} 7.0$ at the scan rate of $0.1 \mathrm{~V} / \mathrm{s}$. As seen at the GOx/GC electrode (curve a), no obvious electrochemical redox peak is observed. It is well known that flavin adenine dinucleotide (FAD) is deeply embedded in a protective protein shell, which makes the direct electron communication with electrodes extremely difficult. Also, the $\mathrm{NH}_{2}-\mathrm{MWCNT} / \mathrm{GC}$ electrode (curve b) and RTIL/ $\mathrm{NH}_{2}$ MWCNT/GC electrode (curve c) did not show any response because they contain no electroactive species. But when GOx was immobilized on the $\mathrm{NH}_{2}$-MWCNT/GC electrode regarding the role of CNTs in facilitating the electron transfer process between the enzyme and electrode surface, a couple of broad redox peaks emerged (curve d). The peaks could be attributed to the $\mathrm{FAD} / \mathrm{FADH}_{2}$ redox couple located in

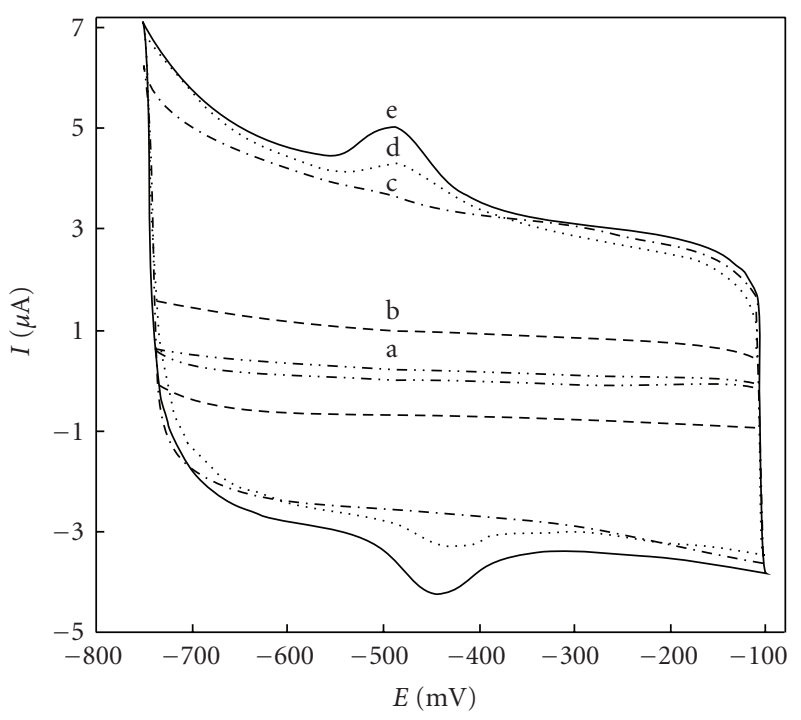

Figure 3: CVs of different modified electrodes: (a) GOx/GC, (b) $\mathrm{NH}_{2}$-MWCNTs/GC, (c) RTIL/NH $\mathrm{N}_{2}$-MWCNTs/GC, (d) GOx/ $/ \mathrm{NH}_{2}-$ MWCNTs/GC, and (e) GOx/RTIL/NH $\mathrm{N}_{2}-\mathrm{MWCNTs} / \mathrm{GC}$. The results

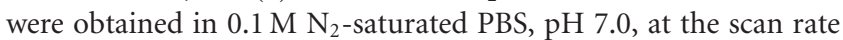
of $0.1 \mathrm{~V} / \mathrm{s}$.

the protein shell. The observed redox response coincided with previously reported $\mathrm{CVs}$ for GOx immobilized on CNTs $[15,16]$. However, the GOx/RTIL/ $\mathrm{NH}_{2}-\mathrm{MWCNT/GC}$ electrode exhibited a well-defined couple of anodic peaks at -440 and cathodic peak at $-495 \mathrm{mV}$ (versus $\mathrm{Ag} / \mathrm{AgCl}$ ). The formal potential $\left(E^{o^{\prime}}\right)$ for $\mathrm{GOx}$ modified electrode as a mean value of anodic $\left(E_{\mathrm{pa}}\right)$ and cathodic $\left(E_{\mathrm{pc}}\right)$ peak potentials was calculated to be $-467.5 \mathrm{mV}$ (versus $\mathrm{Ag} / \mathrm{AgCl}$ ). The peak-to-peak separation, $\Delta E_{p}$, was measured to be $60 \mathrm{mV}$, indicating a fast electron transfer reaction. This is the sign that the RTIL/ $\mathrm{NH}_{2}-\mathrm{MWCNT}$ nanocomposite is able to provide a microenvironment and also to establish an excellent electronic communication between GOx and GC electrode (curve e). Wu et al. [17] have investigated the effect of RTILs as electrolyte on the conformation and electrocatalytic activity of GOx. Their experimental results indicated that $[\mathrm{BMIM}] \mathrm{BF}_{4}$ did not affect on $\mathrm{GOx}$ conformation, but the enzyme electrocatalytic current decreased in the presence of RTIL. In the present work, combination of the RTIL and $\mathrm{NH}_{2}-\mathrm{MWCNT}$ produced a biocompatible nanocomposite by which not only the electrocatalytic activity of GOx did not reduce but also it showed a nearly symmetric redox peak (curve e). As reported previously $[9,10]$, MWCNTs interact with RTILs through $\pi-\pi, \pi$-cationic (the positively charged imidazolium ions) and/or hydrophobic-hydrophobic interactions. In addition, according to Wei et al. [9], RTIL can bind to protein through ionic interaction. As known, at $\mathrm{pH} 7.0$ the net charge of $\mathrm{GOx}$ is negative, and therefore, the anionic functional groups of GOx may show affinity to both the $\mathrm{NH}_{2}$ groups of MWCNTs and the positively charged imidazolium ions of RTIL. Consequently, it seems that these ionic interactions are helpful for adsorption of $\mathrm{GOx}$ on the RTIL/ $\mathrm{NH}_{2}$ MWCNTs nanocomposite. Moreover, the nanocomposite 
led to a relatively fast electronic communication between the enzyme and the modified electrode as shown by curve e.

Figure 4 represents the $\mathrm{CVs}$ of $\mathrm{GOx} / \mathrm{RTIL} / \mathrm{NH}_{2}-$ MWCNTs/GC electrode in $\mathrm{N}_{2}$-saturated PBS at different scan rates. Both the anodic and cathodic peak currents of $\mathrm{GOx}$ are linearly proportional to the scan rate (Figure 4(a)). This suggests that the electrode reaction corresponds to a typical surface-controlled electrochemical process as expected for immobilized systems. The linear regression equation for cathodic $\left(I_{\mathrm{pc}}\right)$ and anodic $\left(I_{\mathrm{pa}}\right)$ peak currents are $I_{\mathrm{pc}}=0.036 \log v+0.3834\left(\mathrm{mV} \mathrm{s}^{-1}, r^{2}=0.9998\right)$ and $I_{\mathrm{pa}}=-0.0327 \log v-0.0908\left(\mathrm{mV} \mathrm{s}^{-1}, r^{2}=0.9991\right)$, respectively. The ratio of $I_{\mathrm{pc}} / I_{\mathrm{pa}}$ was found to be close to the theoretical value of one, as expected for thin-layer electrochemical behavior [18].

As specified by the plot of $E_{p}=f(\log v)$ (Figure 4(b)) at scan rates below $500 \mathrm{mV} \mathrm{s}^{-1}$, the peak separations are almost independent of the potential scan rate indicating a facile charge transfer kinetic over the range of applied sweep rate. But at scan rates above $750 \mathrm{mV} \mathrm{s}^{-1}$, the peak separations begin to increase, indicating the limitation arising from charge transfer kinetics. The kinetic parameters of charge transfer coefficient $(\alpha)$ and apparent charge transfer rate constant $\left(k_{s}\right)$ were calculated using Laviron's equation [19]

$$
\begin{aligned}
\log k_{s}= & \alpha \log (1-\alpha)+(1-\alpha) \log \alpha-\log \left(\frac{R T}{n F \nu}\right) \\
& -\frac{\alpha(1-\alpha) n F \Delta E_{p}}{2.3 R T},
\end{aligned}
$$

$\alpha$ can be calculated using the plot of peak potentials $\left(E_{p}\right)$ versus $\log$ arithm of scan rate $(\log \nu)$. At scan rates above $750 \mathrm{mV} \mathrm{s}^{-1}$, both $E_{\mathrm{pc}}$ and $E_{\mathrm{pa}}$ depend linearly on $\log \nu$. The graph of $E_{p}=f(\log \nu)$ yields two straight lines with slopes of $-2.3 R T / \alpha n F$ and $2.3 R T /(1-\alpha) n F$ for the cathodic and anodic peaks, respectively, where $\mathrm{n}$ is the number of electron and $R, T$, and $F$ have their usual meanings $\left(R=8.314 \mathrm{~J} \mathrm{~mol}^{-1} \mathrm{~K}^{-1}, T=298^{\circ} \mathrm{K}, F=96483 \mathrm{C} \mathrm{mol}^{-1}\right)$. Following these equations, the charge transfer coefficient $(\alpha)$ and the apparent charge transfer rate constant $\left(k_{s}\right)$ for GOx on nanocomposite layer can be calculated to be 0.49 and $2.35 \mathrm{~s}^{-1}$, respectively.

Based on the slope of peak current versus scan rate (Figure 4(a)) and (2), the surface concentration of electroactive proteins on nanocomposite layer $\left(\Gamma_{c}\right)$ was estimated as $2.7 \times 10^{-10} \mathrm{~mol} \mathrm{~cm}^{-2}$. These values are comparable to those reported in the literature [11]

$$
I_{p}=\frac{n^{2} F^{2} v A \Gamma_{c}}{4 R T},
$$

where $n, F$, and $A$ represent the electron transfer number, the Faraday's constant, and the electrode area, respectively [20].

The operational stability of immobilized GOx on RTIL/ $\mathrm{NH}_{2}-$ MWCNTs/GC electrode was evaluated by cyclic voltammetry. The current of redox peak decreased 10\% after 90 cycles at the scan rate of $0.1 \mathrm{~V} / \mathrm{s}$. The biocompatibility of RTIL/ $\mathrm{NH}_{2}-\mathrm{MWCNTs}$ also was considered as the ability of nanocomposite to preserve the GOx storage stability. By

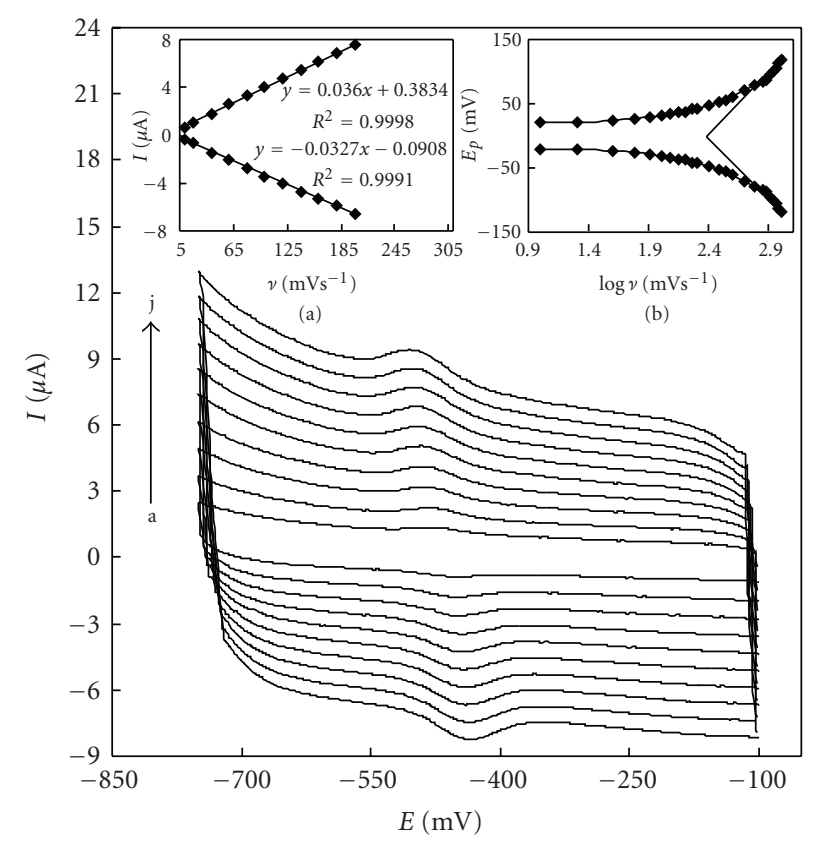

Figure 4: CVs of GOx/RTIL/ $\mathrm{NH}_{2}-\mathrm{MWCNTs} / \mathrm{GCE}$ in $0.1 \mathrm{M} \mathrm{N}_{2}$ saturated PBS, pH 7.0 at various scan rates of 20, 40, 60, 80, 100, $120,140,160,180$, and $200 \mathrm{mVs}^{-1}$ from a to $j$, respectively. Insets represent the plots of $I_{p}$ versus $v$ (a) and $E_{p}$ versus $\log v(\mathrm{~b})$.

storing the prepared enzyme electrode in PBS at $4^{\circ} \mathrm{C}$ for a period of 10 days, $7 \%$ of the current response was lost.

3.3. $p H$ Effect. To control the effect of $\mathrm{pH}$ on the electrochemical behavior of immobilized GOx, a series of experiments were carried out. Figure 5 shows peak currents of the electrode in $\mathrm{N}_{2}$-saturated $\mathrm{PBS}$ at various $\mathrm{pH}$ ranging from 6.2 to 8.2. By increasing the $\mathrm{pH}$, a negative shift was observed in both the reduction and oxidation peak potentials. As illustrated in Figure 5(a), the cathodic peak current increased with the $\mathrm{pH}$ change from 6.2 to 7.0 , then it decreased up to $\mathrm{pH}$ 8.2. According to this plot, $\mathrm{pH} 7.0$ was chosen as the optimal $\mathrm{pH}$ for next experiments. As seen in Figure 5(b), within the $\mathrm{pH}$ range from 6.2 to 8.2 , the slope of $E^{o^{\prime}}$ versus $\mathrm{pH}$ is $61.7 \mathrm{mV} / \mathrm{pH}$ with the regression equation of $y=-0.061 p H-0.038$. This slope is close to the theoretical value of $0.059 \mathrm{~V} / \mathrm{pH}$, as expected for a reversible 2-proton and 2 -electron transfer process at $25^{\circ} \mathrm{C}$.

3.4. Catalytic Activity of Immobilized GOx. The electrocatalytic activity of GOx on RTIL/ $\mathrm{NH}_{2}-\mathrm{MWCNTs} / \mathrm{GC}$ electrode toward glucose was also studied. Figure 6 shows the CVs of the electrode in $\mathrm{O}_{2}$-saturated PBS containing various concentration of glucose. As known, the electrochemical characteristics of GOx modified electrodes are influenced by oxygen [21]. In oxygenated PBS and in the absence of glucose, the enzyme prosthetic group (FAD) is in oxidized form $[21,22]$. Therefore, comparing with Figure 3(e), the oxidation peak height is decreased, while the cathodic peak height is increased. Oxygen molecules can also be reduced at RTIL/NH $\mathrm{NH}_{2}-\mathrm{MWCNTs} / \mathrm{GC}$ electrode in the same potential 


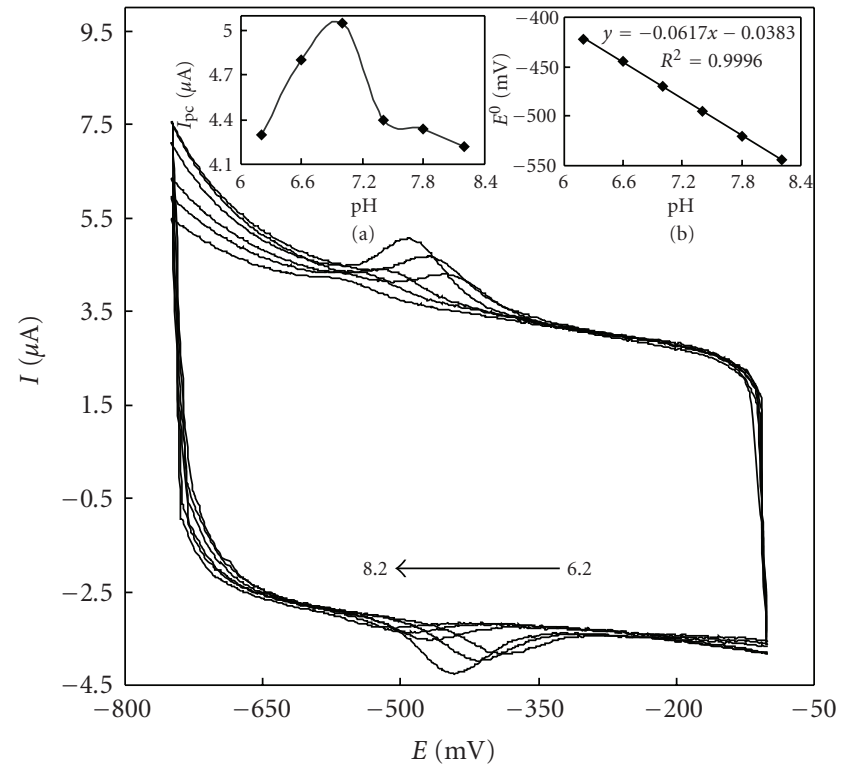

Figure 5: CVs of GOx/RTIL/NH $\mathrm{N}_{2}-\mathrm{MWCNTs} / \mathrm{GCE}$ in $0.1 \mathrm{M} \mathrm{N}_{2}$ saturated PBS at pH 6.2, 6.6, 7.0, 7.4, 7.8, and 8.2 from right to left, respectively. Insets show the plot of $I_{\mathrm{pc}}$ versus $\mathrm{pH}$ (a) and $E^{\circ}$ versus $\mathrm{pH}(\mathrm{b})$.

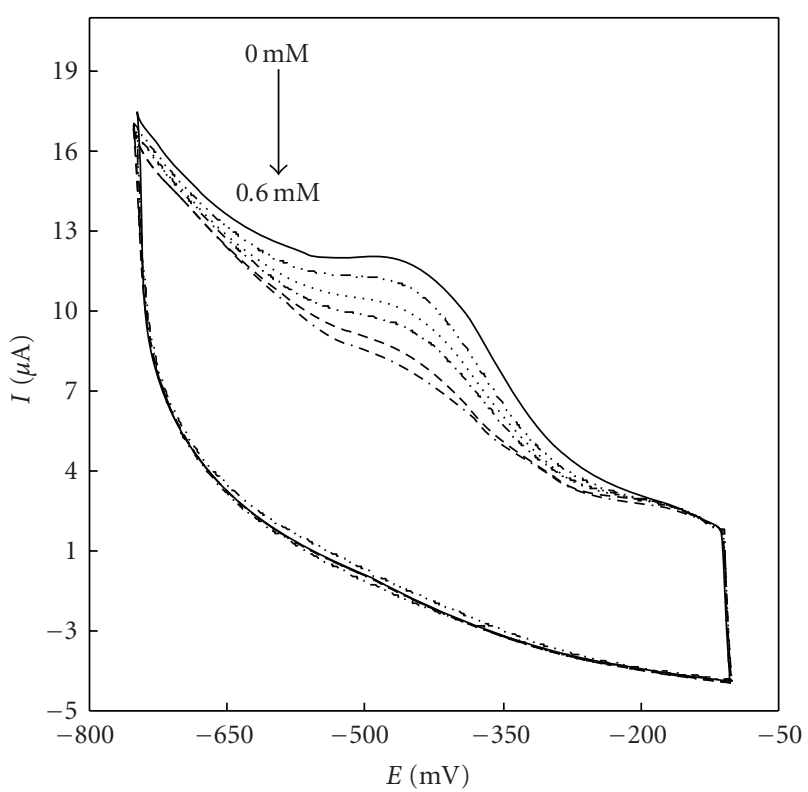

Figure 6: CVs of GOx/RTIL/NH $\mathrm{NH}_{2}$-MWCNTs/GC electrode in $0.1 \mathrm{M}$

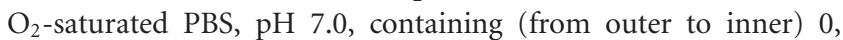
$0.042,0.13,0.22,0.33$, and $0.6 \mathrm{mM}$ glucose at a scan rate of $0.1 \mathrm{~V} / \mathrm{s}$.

window as FAD. Therefore, it seems that both reduction processes of FAD prosthetic group and molecular oxygen contribute to the cathodic peak of Figure 6 (solid curve). By addition of glucose to the PBS, the cathodic peak current height is decreased. As shown in reactions 1 and 2, glucose as the substrate of GOx plays a bifunctional role in decreasing the cathodic peak. By changing the FAD into $\mathrm{FADH}_{2}$, the
FAD (oxidized form) concentration is lessened, and the dissolved oxygen at the electrode surface is also consumed

$$
\begin{gathered}
\mathrm{O}_{2}+\text { glucose } \stackrel{\mathrm{GO}_{\mathrm{x}}}{\longrightarrow} \mathrm{H}_{2} \mathrm{O}_{2}+\text { Gluconolactone, } \\
\mathrm{GOx}(\mathrm{FAD})+\text { Glucose } \longrightarrow \mathrm{GOx}\left(\mathrm{FADH}_{2}\right)+\text { Gluconolactone. }
\end{gathered}
$$

According to these results, it is obvious that the $\mathrm{RTIL} / \mathrm{NH}_{2}$ MWCNTs nanocomposite film not only makes an intimate electronic relationship between enzyme and electrode but also could preserve the electrocatalytic activity of GOx towards glucose oxidation.

3.5. Amperometric Detection of Glucose. To consider the role of ionic liquid in the biosensor efficiency, two modified enzyme electrodes (A and B) were developed, and their analytical parameters were compared. The composition of electrode A was GOx/RTIL/ $\mathrm{NH}_{2}-\mathrm{MWCNTs} / \mathrm{GC}$ and that of $\mathrm{B}$ was $\mathrm{GOx} / \mathrm{NH}_{2}-\mathrm{MWCNTs} / \mathrm{GC}$. Figure 7 illustrates the current time plots of the electrodes at a detection potential of $-510 \mathrm{mV}$ (versus $\mathrm{Ag} / \mathrm{AgCl}$ ) on successive addition of glucose concentrations. The response time (the time during which the electrode current response reaches to a steady state) for the electrodes A and B were 6 and $10 \mathrm{~s}$, respectively. Comparison of these values obviously reveals the role of RTIL in electrode response time enhancement. Interestingly, the amperometric response at each glucose addition step for electrode $\mathrm{A}$ is higher than that for the electrode B. Also, the calibration curves of both electrodes are shown in the insets of Figure 7. The analytical parameters extracted from the calibration curves were listed in last two rows of Table 1 . The current sensitivity was $40.1 \mu \mathrm{AmM}^{-1}$ $\left(1277 \mu \mathrm{A} \mathrm{mM}^{-1} \mathrm{~cm}^{-2}\right)$ for electrode $\mathrm{A}$ and $13 \mu \mathrm{AmM}^{-1}$ $\left(414 \mu \mathrm{A} \mathrm{mM}^{-1} \mathrm{~cm}^{-2}\right)$ for electrode $\mathrm{B}$. These values are much higher than those reported in the literature (Table 1). At a signal-to-noise ratio of $3(\mathrm{~S} / \mathrm{N}=3)$, the detection limits were estimated to be 63 and $393 \mathrm{nM}$ for electrodes $\mathrm{A}$ and $\mathrm{B}$, respectively. These values were lower than the values obtained with the GOx/CHIT/IL/GNPs $(1.5 \mu \mathrm{M})$ [23], the GOx/IL/GNP/IL/SWNTs $(0.8 \mu \mathrm{M})$ [11], and the GOx/MWCNTs/PSS/Au-IL (25 $\mu \mathrm{M})$ [12] (The abbreviations used here are as follows: CHIT: chitosan, GNPs: gold nano particles, SWNTs: single-walled carbon nanotubes, and PSS: poly[sodium 4-styrene-sulfonate]). The results depicted in Table 1 showed that the analytical parameters such as detection limit, sensitivity, and $k_{s}$ were improved by the present research. Also, comparison of the electrode (A and B) responses revealed that the RTIL could enhance the sensitivity and detection limit by 3 and 7 folds, respectively.

The relationship between catalytic current and the concentration of glucose was considered based on the electrochemical version of Michaelis-Menten plot. The enzyme kinetic parameters of apparent Michaelis-Menten constant $\left(K_{m}^{\mathrm{ap}}\right)$ and maximum current $\left(I_{\max }\right)$ measured under substrate saturated concentration can be calculated based on Lineweaver-Burk (5) [24]

$$
\frac{1}{I_{\mathrm{ss}}}=\frac{1}{I_{\max }}+\frac{K_{m}^{\mathrm{ap}}}{I_{\max C}},
$$




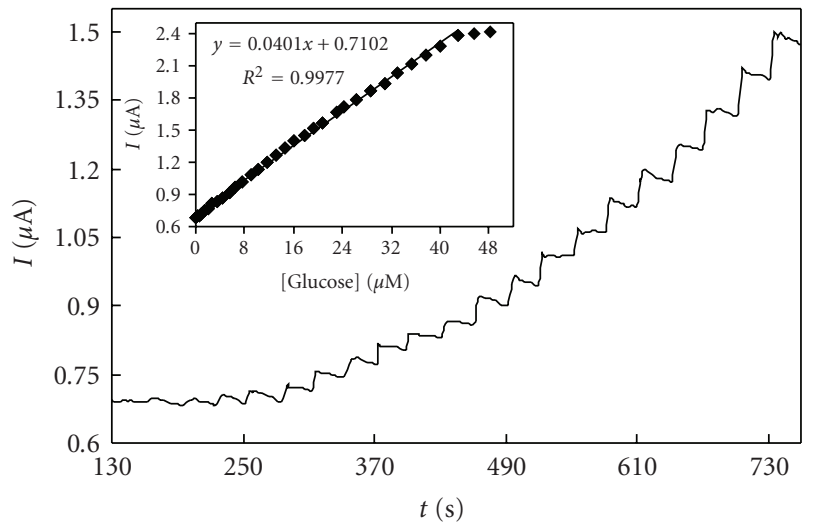

(a)

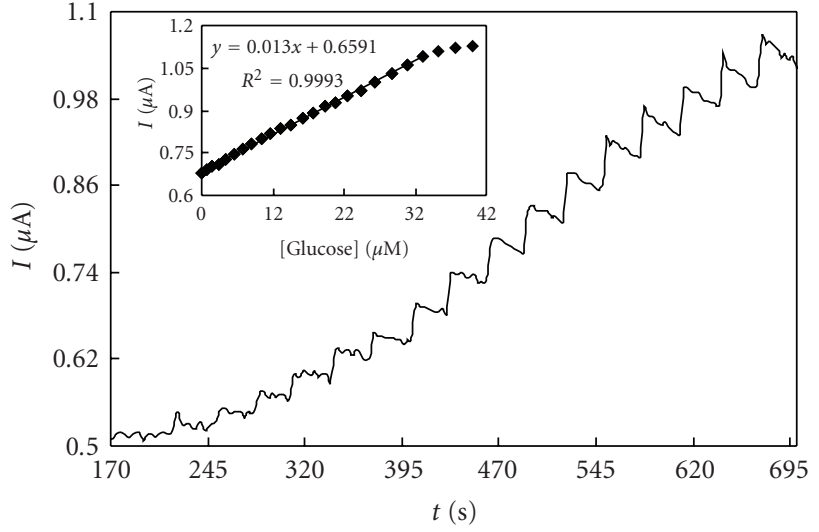

(b)

Figure 7: Amperometric response of GOx/RTIL/NH $\mathrm{NH}_{2}-\mathrm{MWCNTs} / \mathrm{GC}$ (a) and GOx/ $\mathrm{NH}_{2}-\mathrm{MWCNTs} / \mathrm{GC}$ (b) electrodes to glucose. The electrodes were held at $-0.51 \mathrm{~V}$ (versus $\mathrm{Ag} / \mathrm{AgCl}$ ), while its rotation speed was $500 \mathrm{rpm}$ in $0.1 \mathrm{M} \mathrm{PBS}$, $\mathrm{pH} 7.0$. The final concentration of glucose after each successive addition was $0.10,0.25,0.50,0.87,1.36,2.0,2.7,3.5,4.4,5.4,6.5,7.7,9.0,10.3,11.7,13.1,14.6,16.1,17.7,19.3$, $20.9,22.5,24.3,26.4,28.8,31.0,33,35.3,37.6,40,43,45.6$, and $48.3 \mu \mathrm{M}$, respectively. Inset shows the calibration plot for glucose.

TABle 1: Comparison between the analytical parameters of the proposed electrodes and other reported GOx/ionic liquids/nanoparticles based biosensors.

\begin{tabular}{|c|c|c|c|c|c|c|}
\hline GOx-based electrode & Linear range $(\mathrm{M})$ & Detection limit $(\mu \mathrm{M})$ & Sensitivity $\left(\mu \mathrm{A} \mathrm{mM}^{-1}\right)$ & $K_{m}^{\mathrm{ap}}(\mathrm{mM})$ & $K_{s}\left(\mathrm{~s}^{-1}\right)$ & Reference \\
\hline CHIT/IL/AuNPs & $3 \times 10^{-6}-9 \times 10^{-3}$ & 1.50 & 0.450 & 7.800 & - & {$[19]$} \\
\hline IL-GNP-IL-SWNT & $2 \times 10^{-6}-5 \times 10^{-5}$ & 0.80 & - & 0.022 & 2.12 & {$[8]$} \\
\hline MWCNTs/PSS/Au-IL & $0-2 \times 10^{-2}$ & 25.00 & - & - & - & [9] \\
\hline $\mathrm{Au} / \mathrm{CS}-\mathrm{ILMWNT}(\mathrm{SH})$ & $1 \times 10^{-3}-1 \times 10^{-2}$ & - & 4.10 & - & - & {$[10]$} \\
\hline (A) RTIL/NH ${ }_{2}$ MWCNTs & $1.2 \times 10^{-7}-4.3 \times 10^{-5}$ & 0.06 & 40.10 & 0.018 & 2.35 & \multirow{2}{*}{ This work } \\
\hline (B) $\mathrm{NH}_{2}-\mathrm{MWCNTs}$ & $2 \times 10^{-6}-3.3 \times 10^{-5}$ & 0.39 & 13.00 & 0.024 & 2.20 & \\
\hline
\end{tabular}

where $I_{\mathrm{ss}}$ stands for steady state current. From the slope and intercept of the plot, the values of $K_{m}^{\mathrm{ap}}$ and $I_{\max }$ for electrode A were estimated to be $18 \mu \mathrm{M}$ and $2.7 \mu \mathrm{A}$, respectively. The obtained $K_{m}^{\mathrm{ap}}$ value is much smaller than those reported in the literature $[11,23,25,26]$. Such a low $K_{m}^{\text {ap }}$ value could be the sign of higher biological affinity of the biosensor to glucose. Also, comparison of the electrode responses revealed that the RTIL could enhance the $K_{m}^{\mathrm{ap}}$ value for the electrode A (Table 1).

The reproducibility at $10 \mu \mathrm{M}$ glucose concentration was examined between three different electrodes, and the relative standard deviation was calculated to be 3.4 and $6.3 \%$ for electrode A and B, respectively.

\section{Conclusion}

The results obtained in present research showed that the nanocomposite of RTIL/ $\mathrm{NH}_{2}$-MWCNTs/GC could prepare a biocompatible microenvironment to immobilize GOx on modified GC electrode and maintain its activity while facilitate the direct electron transfer between enzyme and electrode surface. The prepared electrode, relative to the similar electrodes reported in the literature, exhibited an extra biocatalytic activity toward glucose with high sensitivity, low detection limit, fast amperometric response, and small value of $K_{m}^{\mathrm{ap}}$. The comparison of the results obtained by the electrode $\mathrm{A}$ with those attained by electrode $\mathrm{B}$ revealed that the ionic liquid [BMIM] $\mathrm{BF}_{4}$ could enhance the sensitivity, detection limit, and $K_{s}$ and $K_{m}^{\mathrm{ap}}$ values of the biosensor.

\section{Acknowledgment}

Financial supports provided by the Research Council of the University of Tehran and Iran National Science Foundation (INSF) are gratefully appreciated.

\section{References}

[1] M. Pumera, S. Sánchez, I. Ichinose, and J. Tang, "Electrochemical nanobiosensors," Sensors and Actuators B, vol. 123, no. 2, pp. 1195-1205, 2007.

[2] J. Wang and M. Musameh, "Carbon nanotube/Teflon composite electrochemical sensors and biosensors," Analytical Chemistry, vol. 75, no. 9, pp. 2075-2079, 2003.

[3] C. E. Banks, T. J. Davies, G. G. Wildgoose, and R. G. Compton, "Electrocatalysis at graphite and carbon nanotube modified electrodes: edge-plane sites and tube ends are the reactive sites," Chemical Communications, no. 7, pp. 829-841, 2005. 
[4] F. Zhao, X. Wu, M. Wang, Y. Liu, L. Gao, and S. Dong, "Electrochemical and bioelectrochemistry properties of roomtemperature ionic liquids and carbon composite materials," Analytical Chemistry, vol. 76, no. 17, pp. 4960-4967, 2004.

[5] S. Hu and C. Hu, "Carbon nanotube-based electrochemical sensors: principles and applications in biomedical systems," Journal of Sensors, vol. 2009, Article ID 187615, 40 pages, 2009.

[6] U. Kragl, M. Eckstein, and N. Kaftzik, "Enzyme catalysis in ionic liquids," Current Opinion in Biotechnology, vol. 13, no. 6, pp. 565-571, 2002.

[7] S. Park and R. J. Kazlauskas, "Biocatalysis in ionic liquidsadvantages beyond green technology," Current Opinion in Biotechnology, vol. 14, no. 4, pp. 432-437, 2003.

[8] R. T. Kachoosangi, M. M. Musameh, I. Abu-Yousef et al., "Carbon nanotube-ionic liquid composite sensors and biosensors," Analytical Chemistry, vol. 81, no. 1, pp. 435-442, 2009.

[9] W. Wei, H. H. Jin, and G. C. Zhao, "A reagentless nitrite biosensor based on direct electron transfer of hemoglobin on a room temperature ionic liquid/carbon nanotube-modified electrode," Microchimica Acta, vol. 164, no. 1-2, pp. 167-171, 2009.

[10] Q. Zhao, D. Zhan, H. Ma et al., "Direct proteins electrochemistry based on ionic liquid mediated carbon nanotube modified glassy carbon electrode," Frontiers in Bioscience, vol. 10, no. 1, pp. 326-334, 2005.

[11] R. Gao and J. Zheng, "Amine-terminated ionic liquid functionalized carbon nanotube-gold nanoparticles for investigating the direct electron transfer of glucose oxidase," Electrochemistry Communications, vol. 11, no. 3, pp. 608-611, 2009.

[12] F. Li, Z. Wang, C. Shan, J. Song, D. Han, and L. I. Niu, "Preparation of gold nanoparticles/functionalized multiwalled carbon nanotube nanocomposites and its glucose biosensing application," Biosensors and Bioelectronics, vol. 24, no. 6, pp. 1765-1770, 2009.

[13] D. Ragupathy, A. I. Gopalan, and K. P. Lee, "Synergistic contributions of multiwall carbon nanotubes and gold nanoparticles in a chitosan-ionic liquid matrix towards improved performance for a glucose sensor," Electrochemistry Communications, vol. 11, no. 2, pp. 397-401, 2009.

[14] P. Rahimi, H. A. Rafiee-Pour, H. Ghourchian, P. Norouzi, and M. R. Ganjali, "Ionic-liquid/NH-MWCNTs as a highly sensitive nano-composite for catalase direct electrochemistry," Biosensors and Bioelectronics, vol. 25, no. 6, pp. 1301-1306, 2010.

[15] C. Cai and J. Chen, "Direct electron transfer of glucose oxidase promoted by carbon nanotubes," Analytical Biochemistry, vol. 332, no. 1, pp. 75-83, 2004.

[16] Y. Liu, M. Wang, F. Zhao, Z. Xu, and S. Dong, "The direct electron transfer of glucose oxidase and glucose biosensor based on carbon nanotubes/chitosan matrix," Biosensors and Bioelectronics, vol. 21, no. 6, pp. 984-988, 2005.

[17] X. Wu, P. Du, P. Wu, and C. Cai, "Effects of 1-butyl3-methylimidazolium tetrafluoroborate on the oxidation of glucose catalyzed by glucose oxidase," Electrochimica Acta, vol. 54, no. 2, pp. 738-743, 2008.

[18] A. J. Bard and L. Faulkner, Electrochemical Methods: Fundamentals and Applications, John Wiley \& Sons, New York, NY, USA, 1980.

[19] E. Laviron, "General expression of the linear potential sweep voltammogram in the case of diffusionless electrochemical systems," Journal of Electroanalytical Chemistry, vol. 101, no. 1, pp. 19-28, 1979.
[20] E. Laviron, "The use of linear potential sweep voltammetry and of a.c. voltammetry for the study of the surface electrochemical reaction of strongly adsorbed systems and of redox modified electrodes," Journal of Electroanalytical Chemistry, vol. 100, no. 1-2, pp. 263-270, 1979.

[21] D. Wang and L. Chen, "Facile direct electron transfer in glucose oxidase modified electrodes," Electrochimica Acta, vol. 54, no. 18, pp. 4316-4320, 2009.

[22] X. Wu, F. Zhao, J. R. Varcoe, A. E. Thumser, C. AvignoneRossa, and R. C. T. Slade, "Direct electron transfer of glucose oxidase immobilized in an ionic liquid reconstituted cellulosecarbon nanotube matrix," Bioelectrochemistry, vol. 77, no. 1, pp. 64-68, 2009.

[23] X. Zeng, X. Li, L. Xing et al., "Electrodeposition of chitosanionic liquid-glucose oxidase biocomposite onto nano-gold electrode for amperometric glucose sensing," Biosensors and Bioelectronics, vol. 24, no. 9, pp. 2898-2903, 2009.

[24] J. Li, S. N. Tan, and H. Ge, "Silica sol-gel immobilized amperometric biosensor for hydrogen peroxide," Analytica Chimica Acta, vol. 335, no. 1-2, pp. 137-145, 1996.

[25] Y. T. Wang, L. Yu, Z. Q. Zhu, J. Zhang, J. Z. Zhu, and C. H. Fan, "Improved enzyme immobilization for enhanced bioelectrocatalytic activity of glucose sensor," Sensors and Actuators B, vol. 136, no. 2, pp. 332-337, 2009.

[26] Y. Zou, L. X. Sun, and F. Xu, "Biosensor based on polyanilinePrussian Blue/multi-walled carbon nanotubes hybrid composites," Biosensors and Bioelectronics, vol. 22, no. 11, pp. 2669-2674, 2007. 


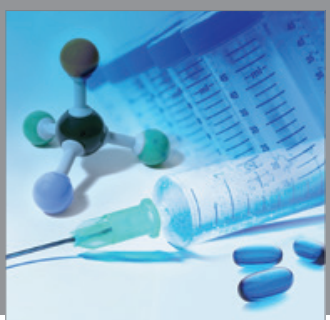

International Journal of

Medicinal Chemistry

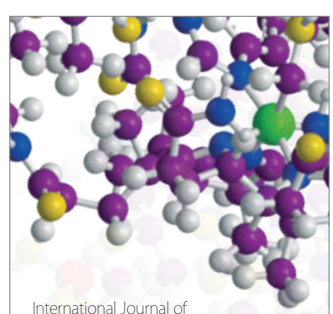

Carbohydrate Chemistry

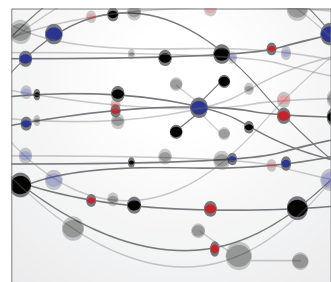

The Scientific World Journal
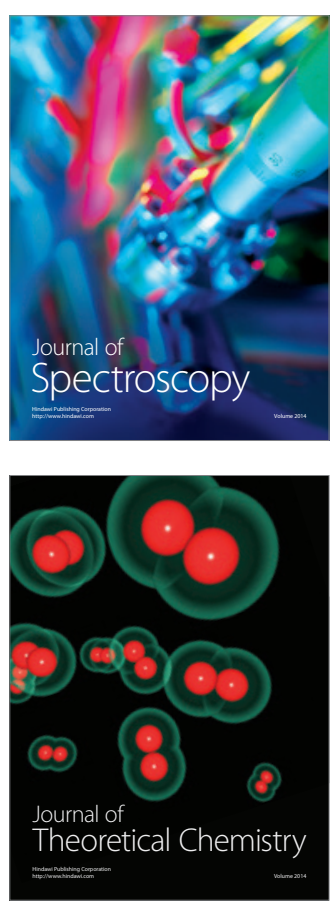
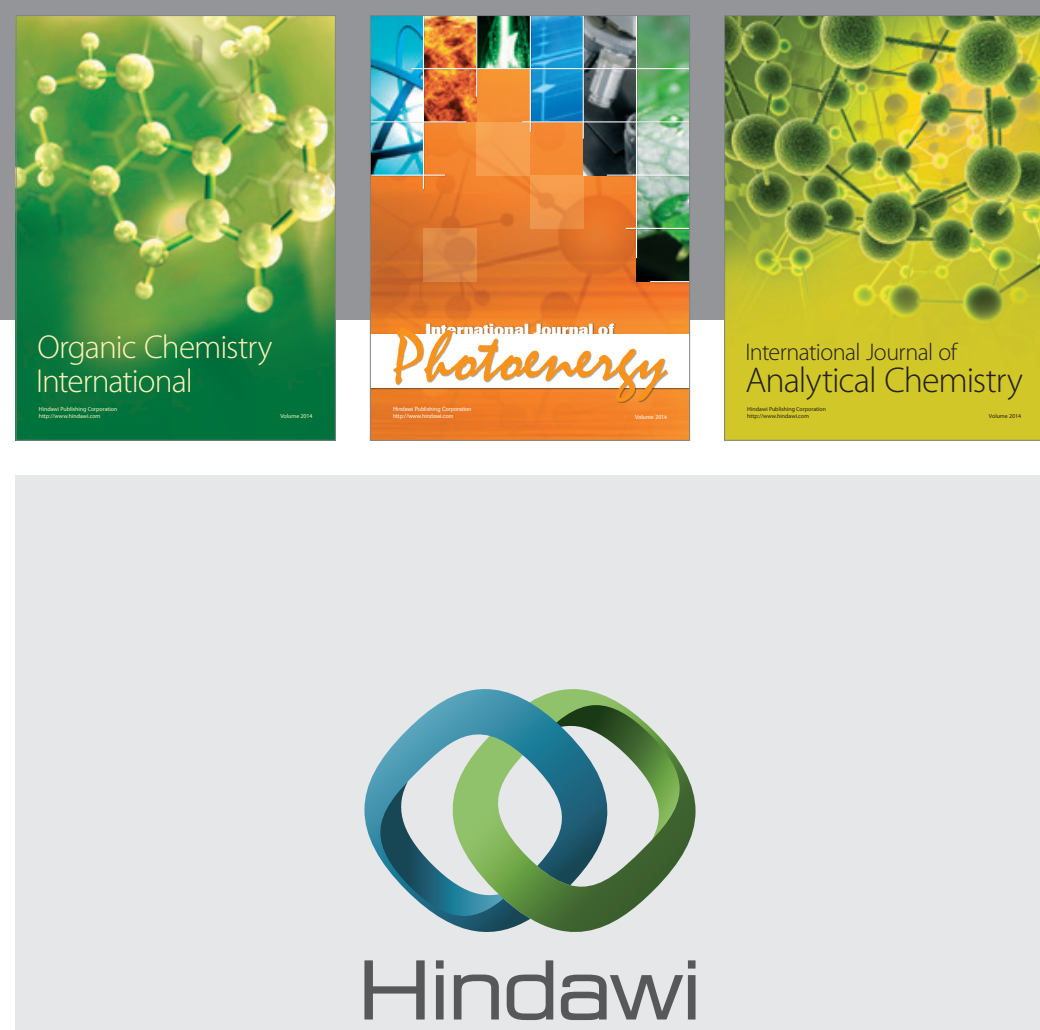

Submit your manuscripts at

http://www.hindawi.com
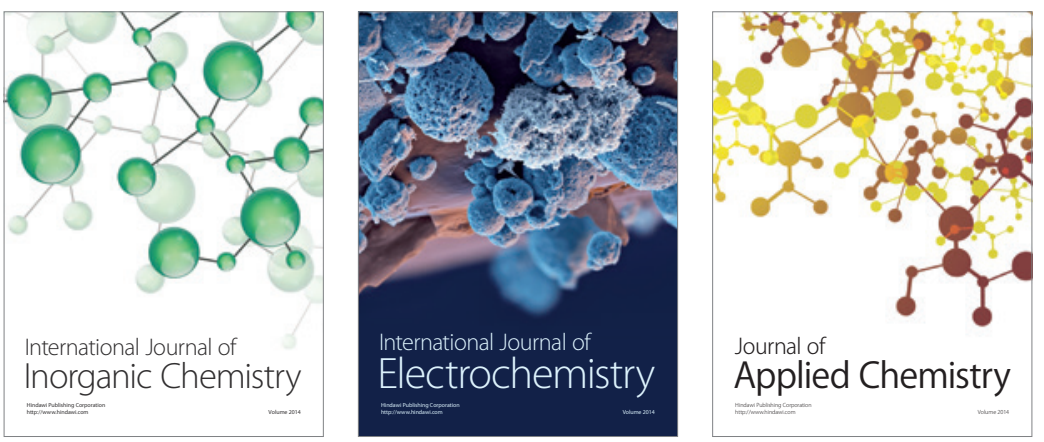

Journal of

Applied Chemistry
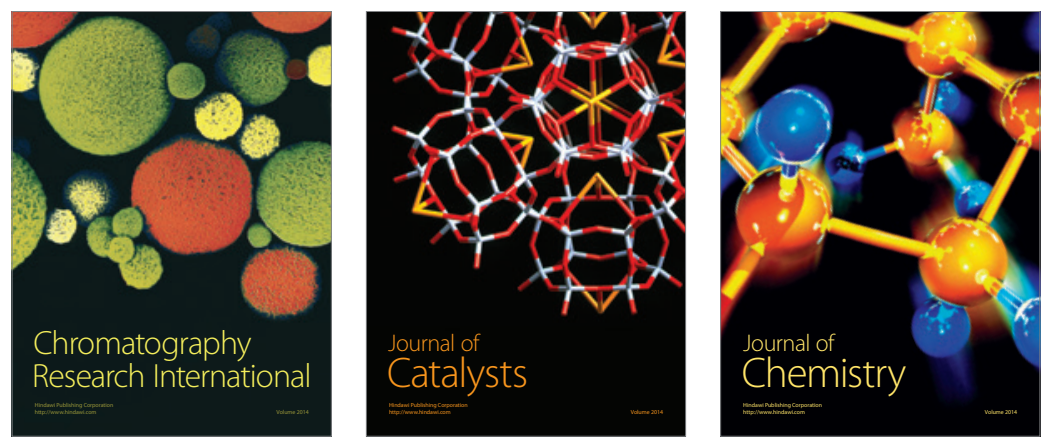
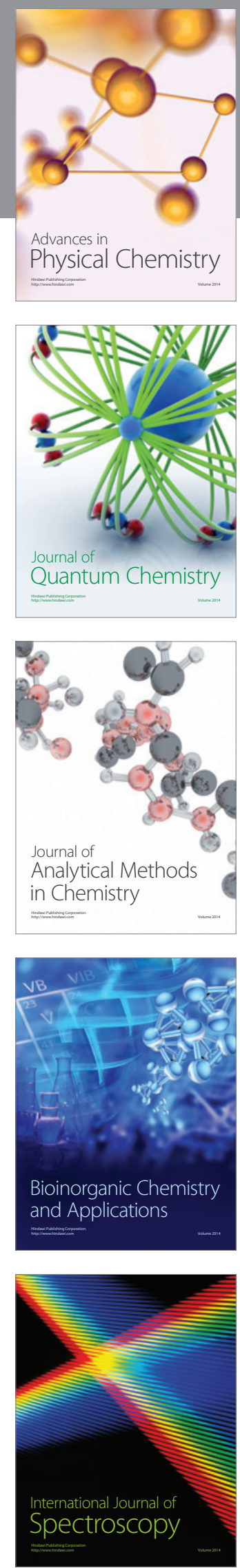